Article

\title{
Study of theoretical Model and Engineering Practice of Coalmine Underground Reservoir Capacity
}

\author{
Jie Fang ${ }^{1,2,3, *}$, Yunlan $\mathrm{He}^{1}$, Shan Chong ${ }^{1}$, Zhenguo Xing ${ }^{1}$, Feisheng Feng ${ }^{1}$, Jiu Huang ${ }^{4}$ and \\ Dongjing $\mathrm{Xu}^{5}$ \\ 1 State Key Laboratory Coal Resources and Safe Mining, China University of Mining and \\ Technology(Beijing),Beijing 100083,China; 55069008@qq.com; 396185870@qq.com; 524799925@qq.com; \\ 1946801809@qq.com \\ 2 State Key Laboratory of Groundwater Protection and Utilization in Coal Mining,China Energy Investment \\ Corporation Limited, Beijing 100011,China \\ 3 Science and Technology Department,China Energy Investment Corporation Limited, Beijing 100011,China \\ 4 State Key Laboratory Coal Resources and Safe Mining, China University of Mining and \\ Technology,Xuzhou 221000,China; jhuang@cumt.edu.cn \\ 5 Shandong Provincial Key Laboratory of Depositional Mineralization \& Sedimentary Minerals, College of \\ Earth Science \& Engineering, Shandong University of Science and Technology, Shandong: Qingdao 266590, \\ China; xudongjinggg@126.com \\ * Correspondence: 10038939@chnenergy.com.cn; Tel.: +86-189-1056-9917
}

\begin{abstract}
The coal mine underground reservoir is an appropriate solution between coal mining and groundwater resource protection and utilization. By calculating the storage capacity of a groundwater reservoir, the storage coefficient has been proved to be always an empirical value. Based on the mathematical derivation of the vertical fracture area ratio and the horizontal fracture area rate of the collapse zone and the fissure zone in the goaf area of the coal seam, the mathematical models of tem are derived, and the model for calculating the water storage coefficient is derived. The water storage coefficient derived from the theoretical model had more basis and more advanced than the traditional empirical value. By using this method, the practical calculation of No.1 underground reservoir of the DaLliuta Coalmine in Shenhua Shendong, has got a perfect matching with the actual groundwater storage capacity.
\end{abstract}

Keywords: Coal mine; Underground reservoir; Reservoir capacity; Theoretical model

\section{Introduction}

Researches have been trying and exploring the use of underground reservoir space [1-5], and the use of underground reservoir space for usage and storage, which has achieved good results in some aspects. For example, a carbonate karst cave was used as the natural gas reservoir [6,7].The fissured storage space formed by underground mining was used to carry out cyclical trials of geothermal energy [8-12]. The underground space was created as the underground reservoir [13]. A certain fissured reservoir space has been formed during the coal mining process, and there have been continuous attempts at utilizing the reservoir space formed by coal mining at home and abroad [1419]. Gu Dazhao proposed the concept of underground protection and utilization of coal with the core of "guiding, storing and using" in the coal-rich and water-scarce Shendong mining area in China(Figure 1), and established a theoretical system to complete the groundwater of 35 coal mines and realize the recycling of coal mine water [17].

There are currently 35 coalmine underground reservoirs in the Shendong Mining Area with a storage capacity of approximately $2.5 \times 10^{7} \mathrm{~m}^{3}$ or more[16]. In the process of construction and use of coal mine underground reservoirs, the determination of reservoir storage capacity not only affects the utilization of the reservoir, but also has certain risks. The actual water storage capacity is less than the storage capacity of the reservoir and leads to the efficiency of the underground reservoir usage. However, the actual water storage capacity is greater than the reservoir capacity, which is prone to 
the danger of permeating the coal mining of the nearby groundwater reservoir. Underground water storage capacity is the product of the reservoir's water storage volume and the water storage coefficient, and the water storage coefficient is derived from the Rule of Mine Prevention and Cure Water Disaster, which is an empirical coefficient. The water storage coefficient is constrained by various factors of coal mining, and it is difficult to accurately calculate the storage capacity of the reservoir. This paper introduces the concepts of vertical and horizontal fissure area rates based on the collapse zone and fissure zone of the goaf after coal mining. Through the establishment of a mathematical model, the values of the vertical and horizontal fissure area ratios were obtained, and the water storage coefficient is derived. It is hoped that it can be used as a reference for the calculation of the precise reservoir capacity of coal mine underground reservoirs.

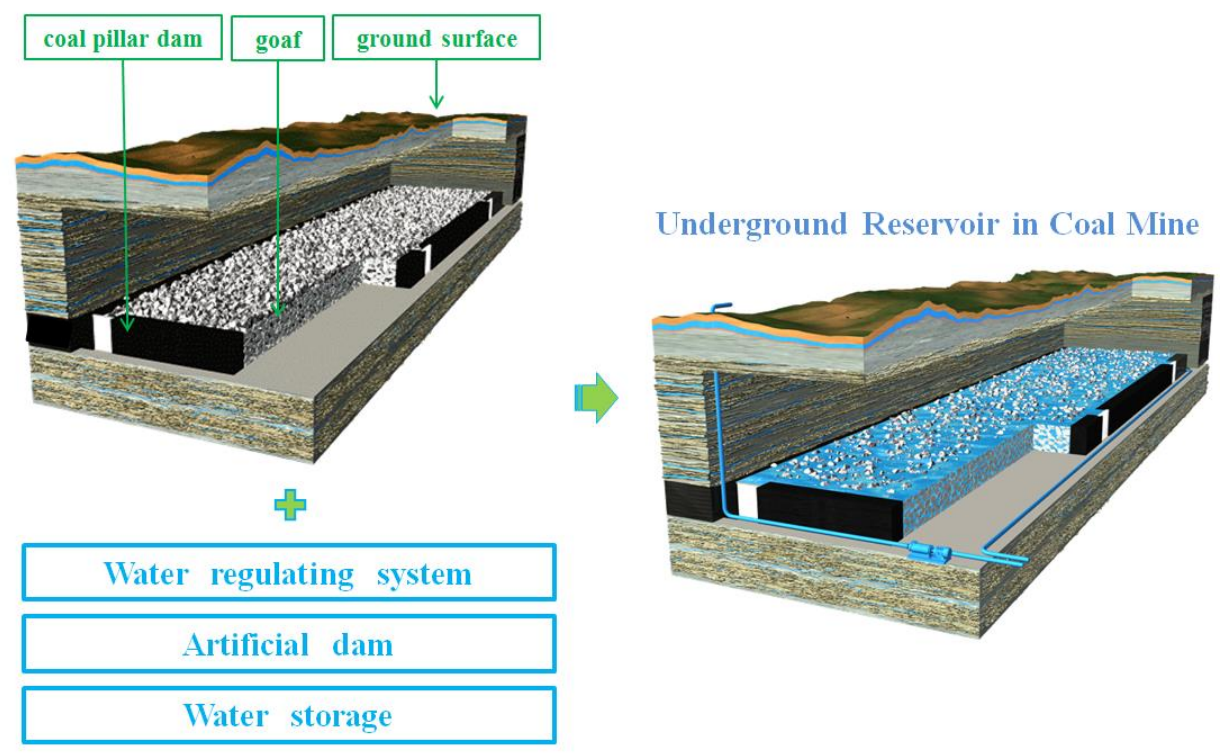

Figure 1. Stratum histogram of the typical working face

\section{Numerical simulation of overburden mining failure}

\subsection{Numerical simulation software}

According to the purpose of the study test and the performances of the numerical simulation software, Itasca's UDEC software was used to simulate the characteristics of the overburden destruction in the mining process of the working face. The rock characteristics of each strata are shown in Figure 2. The joint parameters are selected according to the Coulomb sliding theory in the UDEC joint model, and the value is determined by orthogonal test method. The visual analysis method was used to analyze the parameters of the overburden shown in Table 1 and Table 2. 


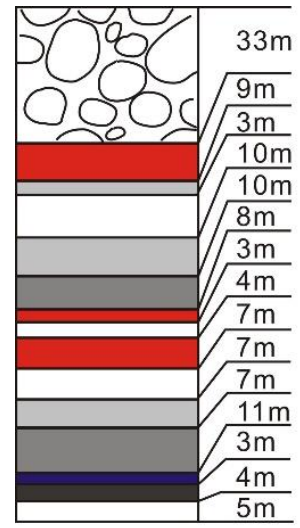

22403 working face

(1)

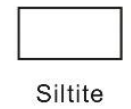

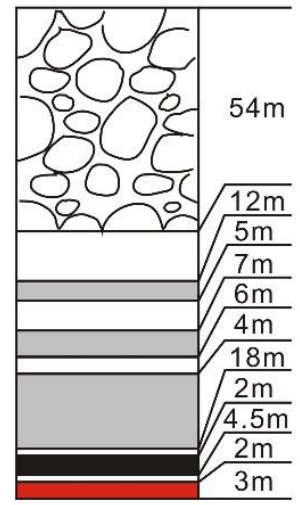

22604 working face

(2)

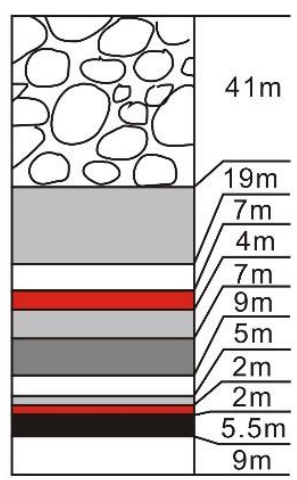

22610 working face

(3)

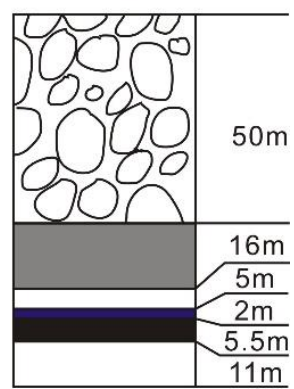

22615 working face

(4)
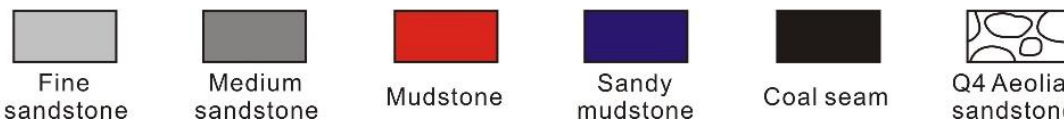

Q4 Aeolian

sandstone

Figure 2. Stratum histogram of the typical working face

Table 1. Mechanical parameters of the coal rock joint face

\begin{tabular}{ccccccc}
\hline Lithology & $\begin{array}{c}\text { Normal } \\
\text { stiffness/ } \\
\text { GPa }\end{array}$ & $\begin{array}{c}\text { Tangential } \\
\text { stiffness/G } \\
\mathbf{P a}\end{array}$ & $\begin{array}{c}\text { Cohesion/ } \\
\mathbf{M P a}\end{array}$ & $\begin{array}{c}\text { Internal } \\
\text { friction } \\
\text { angle / }\end{array}$ & $\begin{array}{c}\text { Tensile } \\
\text { strength } \\
\text { /MPa }\end{array}$ & $\begin{array}{c}\text { Friction } \\
\text { angle/ }\end{array}$ \\
\hline $\begin{array}{c}\text { Siltite } \\
\text { Fine }\end{array}$ & 1.5 & 1.0 & 0.06 & 12 & 0 & 0 \\
$\begin{array}{c}\text { sandstone } \\
\text { Medium }\end{array}$ & 2.3 & 1.3 & 0.04 & 14 & 0 & 0 \\
$\begin{array}{c}\text { sandstone } \\
\text { Sandy }\end{array}$ & 3.4 & 1.7 & 0.03 & 16 & 0 & 0 \\
$\begin{array}{c}\text { mudstone } \\
\text { Mudstone }\end{array}$ & 2.5 & 1.2 & 0.02 & 18 & 0 & 0 \\
$\begin{array}{c}\text { Coal seam } \\
\text { Aeolian }\end{array}$ & 0.6 & 1.2 & 0.02 & 19 & 0 & 0 \\
sandstone & 4.0 & 0.3 & 0.01 & 20 & 0 & 0 \\
\hline
\end{tabular}

Table 2. Physical and mechanical parameters of the overburden

\begin{tabular}{ccccccccc}
\hline Lithology & $\begin{array}{c}\text { Dens } \\
\text { ity/k } \\
\mathbf{g} \cdot \mathbf{m}^{3}\end{array}$ & $\begin{array}{c}\text { Compr } \\
\text { essive } \\
\text { strengt } \\
\mathbf{h} / \mathbf{M P a}\end{array}$ & $\begin{array}{c}\text { Cohesio } \\
\mathbf{n} / \mathbf{M P a}\end{array}$ & $\begin{array}{c}\text { Internal } \\
\text { friction } \\
\text { angle/ }\end{array}$ & $\begin{array}{c}\text { Elasticit } \\
\mathbf{y} \\
\text { modulu } \\
\mathbf{s}\end{array}$ & $\begin{array}{c}\text { Poisson } \\
\text { 's ratio }\end{array}$ & $\begin{array}{c}\text { Bulk } \\
\text { modulu } \\
\text { s }\end{array}$ & $\begin{array}{c}\text { Shear } \\
\text { modulu } \\
\text { s }\end{array}$ \\
\hline $\begin{array}{c}\text { Aeolian } \\
\text { sandstone } \\
\text { Mudstone }\end{array}$ & 1700 & 12.0 & 0.02 & 20 & 12.0 & 0.30 & 10.00 & 4.62 \\
$\begin{array}{c}\text { Sandy } \\
\text { mudstone }\end{array}$ & 2430 & 45.94 & 5.55 & 29 & 10.09 & 0.15 & 4.80 & 4.39 \\
$\begin{array}{c}\text { Siltite } \\
\text { Fine }\end{array}$ & 2450 & 32.65 & 6.82 & 38 & 10.28 & 0.17 & 5.19 & 4.39 \\
$\begin{array}{c}\text { sandstone } \\
\text { Medium }\end{array}$ & 2410 & 35.04 & 6.46 & 38 & 13.16 & 0.2 & 7.31 & 5.48 \\
$\begin{array}{c}\text { sandstone } \\
\text { and }\end{array}$ & 2340 & 22.07 & 5.81 & 39 & 11.35 & 0.24 & 7.28 & 4.58
\end{tabular}


Coal seam 1320 13.5 1.0 30 13.0 0.26 9.03

\subsection{Characteristics of overburden failure}

The damage characteristics of overlying strata during the mining of working face are shown in Figure 3. When the advancing distance of the working face was $20 \mathrm{~m}$, immediate roof began to fall and ran through the immediate roof sandy mudstone layer, and partially falls. The height of the falling belt was about 3-4 m; When the working surface was advanced up to $50 \mathrm{~m}$, the falling belt continues to expand upwards to the middle sandstone layer. The lower part of the middle sandstone layer starts to fall. The height of the falling belt was approximately 7-9 m; Due to the large thickness of the middle sandstone layer, the height of the falling belt no longer developed upward during excavation to $100 \mathrm{~m}$; When the working surface was propelled by a distance of $150 \mathrm{~m}$, the falling belt continued upwards, basically stabilizing on the top surface of the middle sandstone layer, and the height of the falling belt was about 12-14 m. Fallen rock deformations gradually filled the goaf area, and within a certain range of rock deformations, the rock strata began to split along the stratification to form the separation layer (the crack from the strata). And a large number of cracks (breaking gaps) that were perpendicular or oblique to rock formations are generated under tensile stress, and the height was 50-54 m; The upper rock layer moved in an integrated manner, generally no pull failure occurs, and normal bending occurred only under the action of its own weight. The rock body maintained its original integrity and entered the curved sinking belt.

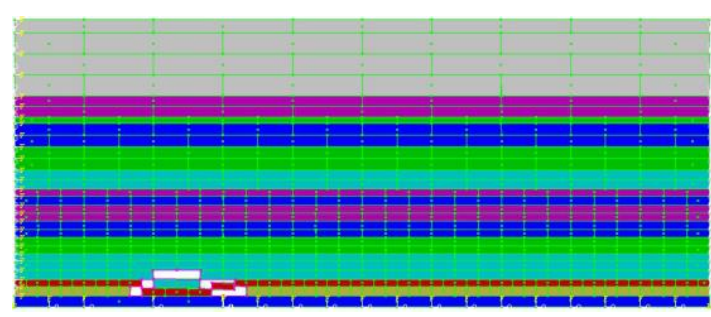

(a)

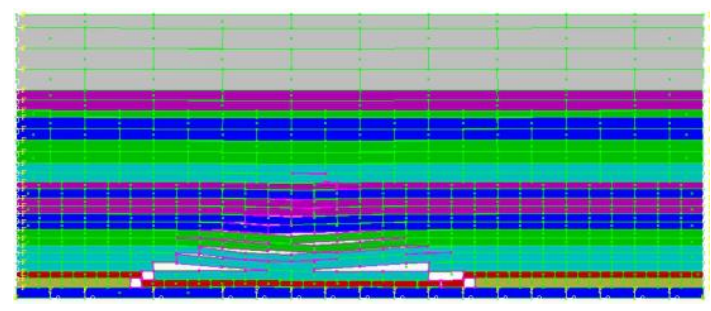

(c)

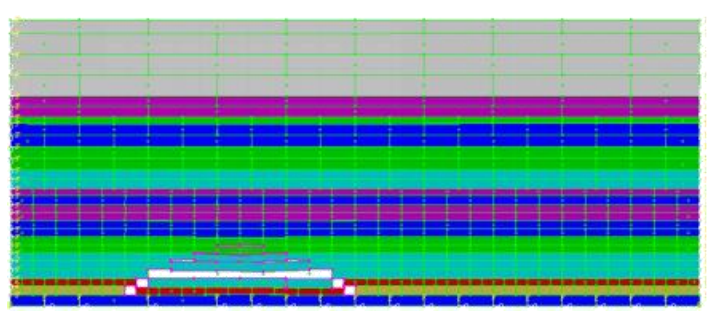

(b)

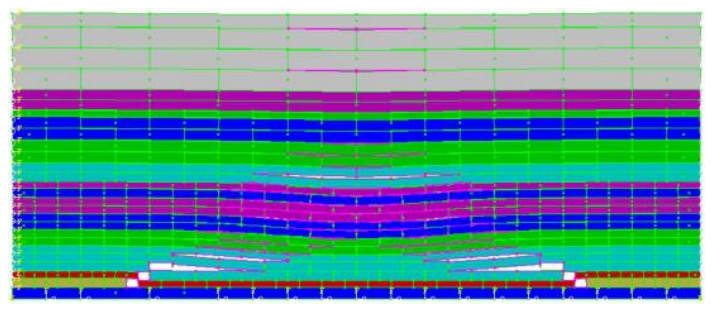

(d)

Figure 3. (a) Characteristics of overburden failure when working face advance distance was $20 \mathrm{~m}$; (b) Characteristics of overburden failure when working face advance distance was $50 \mathrm{~m}$; (c) Characteristics of overburden failure when working face advance distance was $100 \mathrm{~m}$; (d) Characteristics of overburden failure when working face advance distance was $150 \mathrm{~m}$.

Through analysis, it can be seen that during the advancing of working face, the shear failure of the coal seam roof occurs first, thereby promotes the continuous development of cracks. When the working surface pushing distance exceeds the initial pressure, the direct roof begins to fall and the old roof gradually forms a structure. The height of the falling belt formed by coal mining is 12-14 $\mathrm{m}$, and the height of the crack zone is 55-60 m. During the advancement of the work surface, the direct roof and the old roof appear cyclical decline, and the falling rock layers in the goaf area are gradually compacted. However, in the range of $40-50 \mathrm{~m}$ on both sides, there is still a relatively obvious vertical breaking gap, that is, there is a certain range of crack development areas around the goaf. 
To further study the settlement of the overburden and the development of the bed separated fracture, the displacement data of strata at different heights from the coal seam roof were extracted, and the corresponding settlement curves of the overburden were made, as shown in Figure 4.

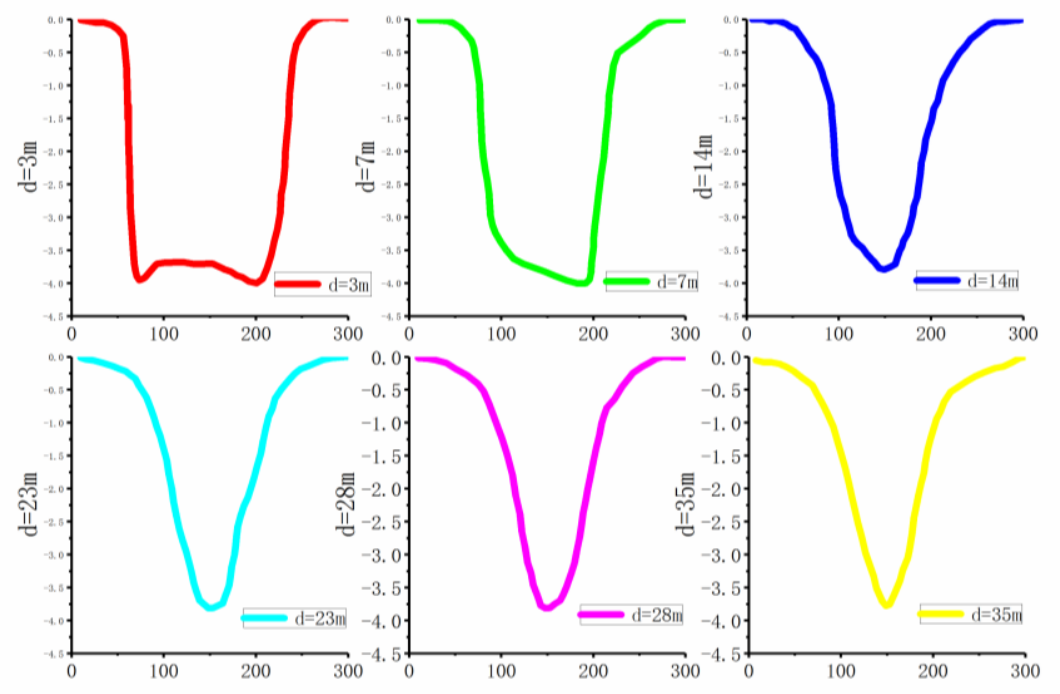

Figure 4. Settlement curves of the overburden.

The settlement curve of the rock shows that after the excavation was completed, the settlement of the immediate roof strata reaches the height after the excavation, and the displacement at the front section and the opening at the work was small. The settlement curve was approximately " $U$ " and gradually decreased upwards. The settlement curve gradually shifted to the "V" type. The maximum subsidence of each rock formation was inversely proportional to its distance from the roof; with the increase of the distance from the roof of the coal seam, the overlying rock deformations were successively displaced from the bottom to the top, the settlement was non-linear, and the moving form was asymmetric.

According to the overburden failure after complete caving, the angle between the fractured surface and the roof plane that was formed in the direction of goaf after roof caving, namely the caving angle, was calculated to be $60^{\circ}$.

\section{Establishment of theoretical model}

Rock fractures (or cracks) caused by mining activities are called mining cracks. According to the size and shape of the fracture, it can be divided into horizontal and vertical fractures. Segregation cracks were mainly caused by the non-synchronization of the rock subsidence. The direction is generally along the direction of the working surface and the length is large. Longitudinal fissures are mainly due to shear or extension of rock formations. They are generally vertical or nearly perpendicular to rock formations, and they are small in length and may penetrate through the upper and lower rock formations locally (Figure 5(a)). In the falling zone, cracks in the cracked rock mass are the main water storage space of the underground reservoir. 

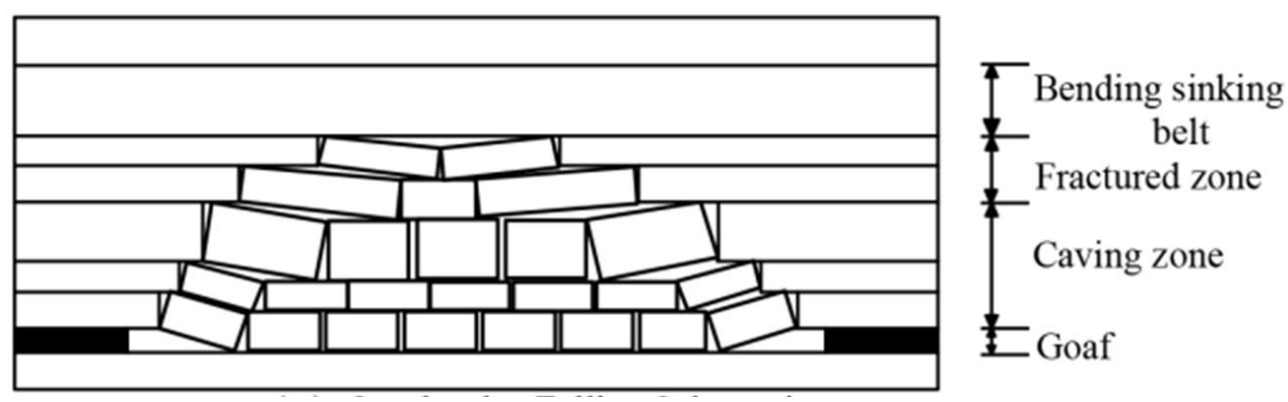

(a)
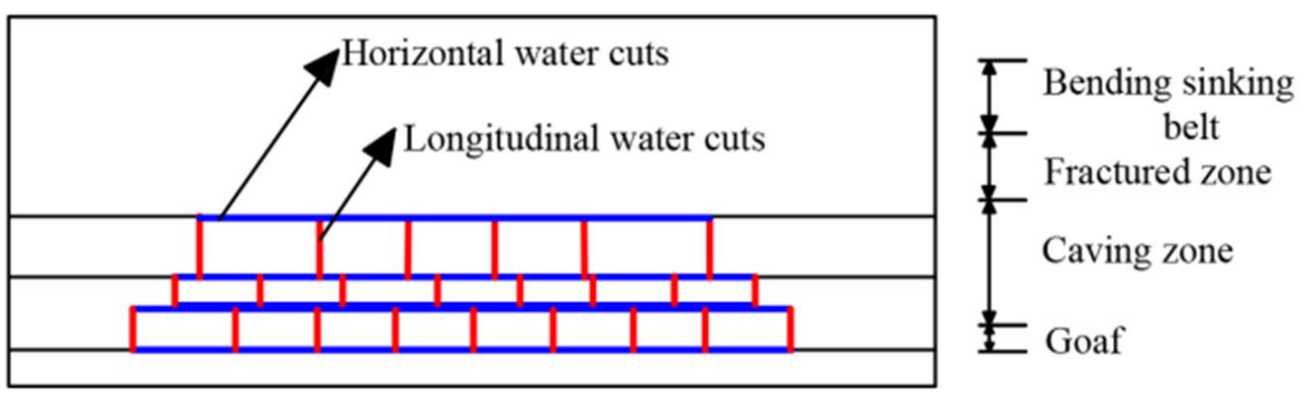

(b)

Figure 5. Diagram of the overburden caving and water storage space: (a) Overburdun falling schematic; (b)

Water storage area schematic.

The reservoir volume $(\mathrm{F})$ was the volume of disintegrated rock mass within the groundwater reservoir, and the water storage coefficient $(\alpha)$ is the fracture volume fraction of the disintegrated rock mass within the mined area.

The underground reservoir capacity can be expressed as:

$$
\text { Reservoir capacity }(\mathrm{V})=\text { reservoir volume }(\mathrm{F}) \text { xwater storage coefficient }(\alpha)
$$

The storage capacity was a function of the water level. As the water level increases, the storage capacity increases gradually. In the calculation of reservoir capacity, it is assumed that the number of strata in the strata within the falling zone $(\mathrm{Hm})$ is $\mathrm{n}_{1}$; the number of strata below a certain water level $(\mathrm{Hw})$ after the reservoir is stored is $\mathrm{n}_{2}$.

It was assumed that the vertical fracture was a flat, smooth, plane perpendicular to the direction of advancement of the working face, and the horizontal fracture was a horizontal, smooth plane. The water storage coefficient can be equivalent to the area ratio of the fissure in the falling zone above the goaf on the section along the mining direction (Figure 5(b)).

Water storage coefficient $(\alpha)=$ vertical fracture area $\operatorname{ratio}\left(\alpha_{1}\right)+$ horizontal fracture area $\operatorname{ratio}\left(\alpha_{2}\right)$.

\subsection{Vertical fracture area ratio}

Assuming the rock was homogeneous and isotropic, the initial pressure step distance was $l_{1}$, the number of vertical fractures produced by the initial pressure was $\mathrm{n}_{1}$, the periodic pressure step distance was $1_{2}$, only one vertical fracture was produced by each periodic pressure, the thickness of coal seam was $H$, the width of vertical fracture was $\delta$, and the length of working face was $L$.

Vertical fracture area ratio. 


$$
\alpha_{1}=\left(\frac{L-l_{1}}{l_{2}}+n_{1}\right) \cdot \delta / L
$$

The initial pressure step: As shown in Figure 6, for the collapse caused by the initial pressure, the two-dimensional elastic mechanics model was: the simply supported beam under the uniform load q1.

According to the mechanics theory of materials, for a simply supported beam with rectangular section (height $h$, width $b$ ) and span 1 under uniform load $\mathrm{q}_{1}$, and the maximum bending moment was at the center of the span, which was: $M_{\max }=\frac{1}{8} q_{1} l^{2}$.

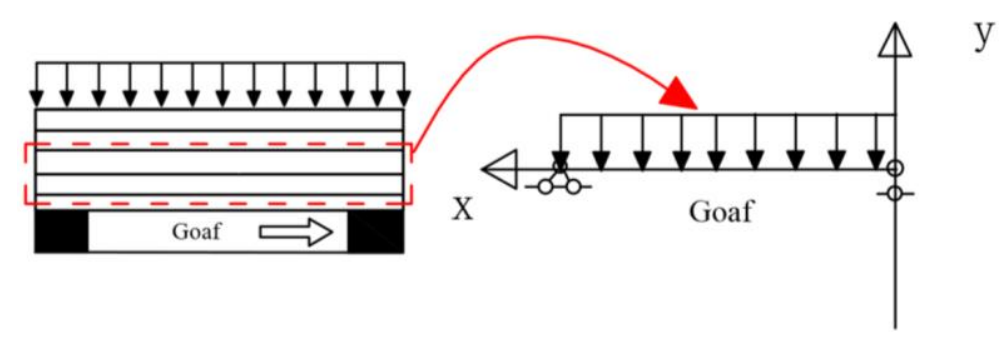

Figure 6. Initial pressure and its mechanics model.

The maximum bending normal stress was at the center of the span, which was: $\sigma_{\max }=\frac{M_{\max }}{I_{2}} \bullet \frac{h}{2}$.

At the top of the beam was the compressive stress, and at the bottom of the beam was the tensile stress.

Took $\sigma_{\max }=\sigma_{\tau}=\frac{1}{10} \cdot \sigma_{c}$, for the rectangular section $I_{z}=\frac{b h^{3}}{12}, l_{\max }=\sqrt{\frac{4 b h^{3}}{3 q_{1}} \cdot \frac{\sigma_{c}}{10}}$ was obtained, namely the initial pressure step distance.

$$
l_{1}=\sqrt{\frac{4 b h^{3}}{3 q_{1}} \cdot \frac{\sigma_{c}}{10}}
$$

In the above formula, the key is to determine the line load $\mathrm{q}_{1}$ to which the direct top is subjected. According to the principle of combined rock beam, the formula for calculating the surface load of the immediate roof was:

$$
\left(q_{n}\right)_{1}=\frac{E_{1} h_{1}^{3}\left(r_{1} h_{1}+r_{2} h_{2}+\Lambda+r_{n} h_{n}\right)}{E_{1} h_{1}^{3}+E_{2} h_{2}^{3}+\Lambda+E_{n} h_{n}^{3}}
$$

Where $\left(q_{n}\right)_{1}$ was the load of the nth stratum above the immediate roof acting on the immediate roof rock, $\mathrm{KPa} ; E_{n}$ was the elasticity modulus of the immediate roof and overburdens, $\mathrm{MPa} ;{ }_{n}$ was the thickness of the immediate roof and overburdens, $\mathrm{m} ;{ }_{n}$ was the gravity of the immediate roof 
and overburdens, $\mathrm{KN} / \mathrm{m}^{3}$. When $\left.q_{n+1}\right)_{1}<\left(q_{n}\right)_{1}$ was calculated, the surface load of the overburdens acting on the immediate roof, namely $\left(q_{n}\right)_{1}$, was adopted. According to the relationship between the surface load and line load, $q_{1}=b \cdot\left(q_{n}\right)_{1}$, $\mathrm{b}$ was the length perpendicular to the line load, that is, the width of the working face, and $\mathrm{q}_{1}$ can be obtained.

Cycle to press the step: As shown in Figure 7, for the cycle of pressure generated by the fall, the two-dimensional elastic mechanics model: Under the uniform load q2, the right end rigid junction cantilever beam.

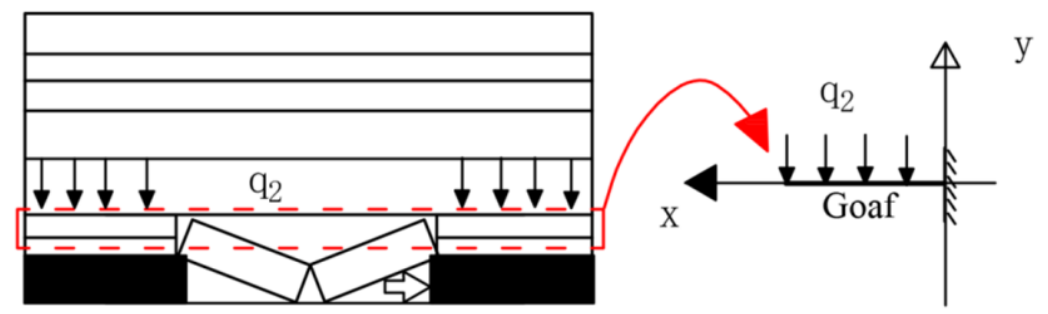

Figure 7. Periodic pressure and its mechanics model.

According to the mechanics theory of materials, for a cantilever beam with rectangular section (height $h$, width $b$ ) and span 1 under uniform load q2, and the maximum bending moment was at the fixed end, which was: ${ }^{M_{\max }}=\frac{1}{2} q_{2} l^{2}$.

The maximum bending normal stress was at the fixed end, which was: ${ }^{\sigma_{\max }}=\frac{M_{\max }}{I_{z}} \cdot \frac{h}{2}$. At the top of the beam was the compressive stress, and at the bottom of the beam was the tensile stress.

Took $\sigma_{\max }=\sigma_{\tau}=\frac{1}{10} \cdot \sigma_{c}$, for the rectangular section $I_{z}=\frac{b h^{3}}{12} l_{\max }=\sqrt{\frac{b h^{3}}{3 q_{2}} \cdot \frac{\sigma_{c}}{10}}$ was obtained, namely the periodic pressure step distance.

$$
l_{2}=\sqrt{\frac{b h^{3}}{3 q_{2}} \cdot \frac{\sigma_{c}}{10}}
$$

After the initial caving of the immediate roof, in the subsequent mining, stress concentration occurs in the front section of the work, and the stress concentration factor $\lambda$ is related to the roof lithology. Generally, the mudstone was 1.3 , the sandy mudstone was 1.4, and the sandstone was 1.5. In the calculation process, the stress concentration factor was reasonably selected according to the lithology of the immediate roof, $\mathrm{q}_{2}=\lambda \times \mathrm{q}_{1}$.

Vertical crack width $\delta$ : The geometric characteristics of the block displacement in the initial collapse are shown in Figure 8. 


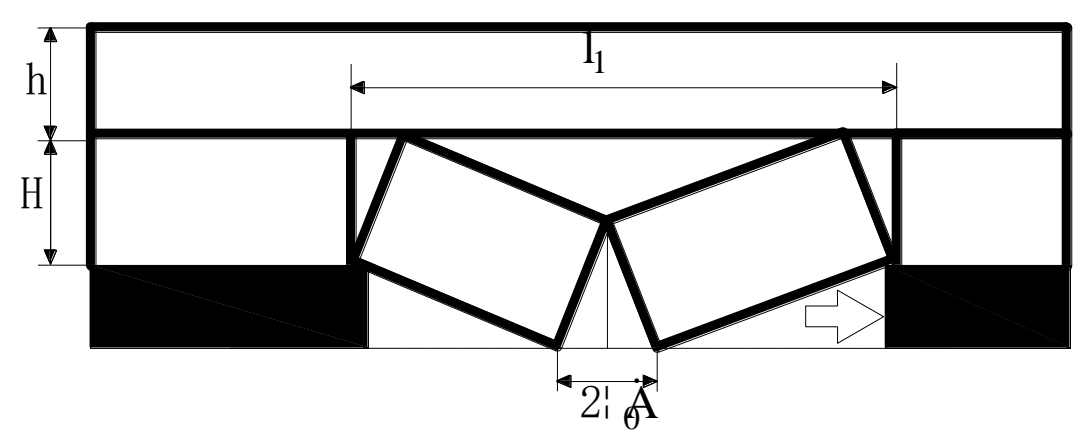

Figure 8. Diagram of the initial caving of the immediate roof.

According to the mathematical relationship: $H^{2}+\left(\frac{1}{2} l_{1}-\delta_{0}\right)^{2}=\left(\frac{1}{2} l_{1}\right)^{2}$.The maximum opening $\Delta$ of the vertical fracture after periodic caving was: $\delta_{0}=\frac{1}{2} l_{1}-\sqrt{\left(\frac{1}{2} l_{1}\right)^{2}-H^{2}}$.

Considering the collapse of the overlying strata, the compaction of the vertical fractures is compacted and the final vertical crack width is taken as $\delta=0.5 \delta_{0}$, that is:

$$
\delta=0.5 \times\left(\frac{1}{2} l_{1}-\sqrt{\left(\frac{1}{2} l_{1}\right)^{2}-H^{2}}\right)
$$

\subsection{Horizontal fracture area ratio}

Assuming that the horizontal fissure was a horizontal thin layer of thickness $b$, the vertical stress was generally three times of the horizontal stress, so the thickness of the horizontal fissure was $1 / 3$ of the vertical fissure. The number of strata below a certain water level (Hw) after the impoundment of the reservoir was $n_{2}$. In the section along the working surface, the horizontal fissure area rate.

$$
\alpha_{2}=\frac{b \cdot L \cdot n_{2}}{L \cdot H_{w}}=\frac{b \cdot n_{2}}{H_{w}}
$$

\subsection{Reservoir volume}

Reservoir volume refers to the volume of disintegrated rock mass within the scope of the underground reservoir. After the overlying strata collapsed, the range of the fall zone decreased progressively from top to bottom, with a sag angle of $\theta$. The advancing distance of the coal face was L, and B was the width of the face. After a reservoir is filled with water, the volume of fragmented rock mass at a certain water level $(\mathrm{Hw})$ is equivalent to the model in the figure (Figure 9).

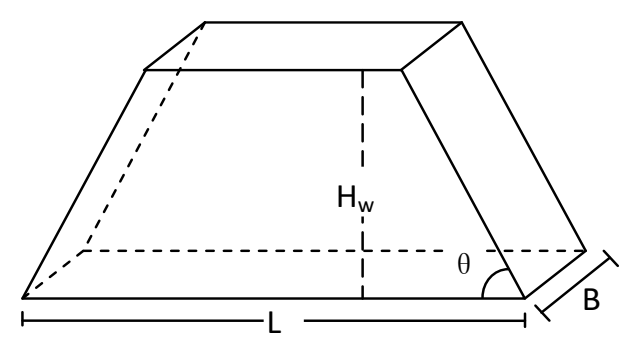

Figure 9. Diagram of the reservoir volume.

According to the mathematical relationship, the reservoir volume can be expressed as: 


$$
F=H_{w} \cdot B \cdot\left(L-H_{w} \cot \theta\right)
$$

\section{Engineering practice}

\subsection{Practice of underground reservoir in Daliuta Coal Mine}

The Daliuta mine field is located on the east bank of the midstream of the Wulanmulun River. The terrain is high in the north and low in the south, and the eastern and northern branches of the ditch are developed. The bedrock in the north is bare and the maximum height difference is $216 \mathrm{~m}$. The main aquifer in well field is in the alluvial layer of the Quaternary river valley in the Wulan Mulun River and the Breuchuan River Basin. The Quaternary Pleistocene Sarah Soo group, mainly located in the lower-lying areas of the area. It is mainly distributed in the middle part of the well field, which is located on the basement rock and below the silt-loess layer. The Quaternary Lower Pleistocene Sanmen Group gravel layer aquifer, and the layer is partially in direct contact with the Quaternary loose sand layer, with a thickness of 0-27.4 m, an average thickness of $11.77 \mathrm{~m}$, and an aquifer thickness of 0.10-27.48 m, with an average of $8.24 \mathrm{~m}$. There are also clastic rock fractured aquifers in the Mesozoic, which are mainly exposed in the Hara Gully, the Muhegou and the Wangqugou.

The first goaf storage facility in Daliuta Coal Mine was completed in 1998. On the basis of the water storage technology in the goaf, through continuous technological innovation, a "circular, environment friendly, energy-saving and efficiency" distributed underground reservoir of coal mine that makes full use of the goaf space to store water, filters and purifies the water body by gangue in the goaf, and transports water by natural pressure difference was built in two levels in 2010. With the underground water supply, underground drainage, mine water treatment, flood control, environmental protection and energy-saving emission reduction 6 major functions.

\subsection{Calculation of underground reservoir capacity}

The direct top of Reservoir No. 1 is sandy mudstone, with thickness $\mathrm{h}=3 \mathrm{~m}$, compressive strength of $\sigma_{c}=32.65 \mathrm{MPa}$, working face width $\mathrm{B}=200 \mathrm{~m}$, combined with the stratification of the strata in Figure 1, and the physical and mechanical parameters of coal and rock in Table 1. According to formula (1) there are:

Sandy mudstone: $\left(q_{1}\right)_{1}=r_{1} h_{1}=73.8 \mathrm{KPa}$

Medium sandstone: $\quad\left(q_{2}\right)_{1}=\frac{E_{1} h_{1}\left(r_{1} h_{1}+r_{2} h_{2}\right)}{E_{1} h_{1}^{3}+E_{2} h_{2}^{3}}=6.08 \mathrm{KPa}$

$\left(\mathrm{q}_{2}\right) 1<\left(\mathrm{q}_{1}\right) 1$, thus $\mathrm{q}_{1}=\left(\mathrm{q}_{1}\right) 1^{*} \mathrm{~b}=73.8^{*} 200 \mathrm{KN} / \mathrm{m}$. By substituting it into the Formula (3), the initial pressure step distance was obtained:

$$
l_{1}=\sqrt{\frac{4 b h^{3}}{3 q_{1}} \bullet \frac{\sigma_{c}}{10}}=23.04 \mathrm{~m}
$$

The immediate roof was sandy mudstone, with the stress concentration factor of $\lambda=1.4$, $\mathrm{q}_{2}=\lambda \times \mathrm{q}_{1}=20,664 \mathrm{KN} / \mathrm{m}$. By substituting it into the Formula (5), the periodic pressure step distance was obtained:

$$
l_{2}=\sqrt{\frac{b h^{3}}{3 q_{2}} \cdot \frac{\sigma_{c}}{10}}=9.7 \mathrm{~m}
$$


The average thickness of 2-2 coal mine No. 1 underground reservoir within the horizontal range was $\mathrm{H}=4 \mathrm{~m}$. By substituting it into the Formula (6), the width of the vertical fracture after compaction was obtained:

$$
\delta=0.5 \times\left(\frac{1}{2} l_{1}-\sqrt{\left(\frac{1}{2} l_{1}\right)^{2}-H^{2}}\right)=0.358 \mathrm{~m}
$$

Assuming only one fracture was produced by initial pressure in the middle and front and back coal wall, that is, $n_{1}=3$. According to the Formula (2), the calculation results of the vertical fracture area ratio are shown in Table 3.

Table 3. Vertical fracture area ratio

\begin{tabular}{ccc} 
Working face number & Working face advance distance $\mathbf{L}(\mathbf{m})$ & Vertical fracture area ratio $\boldsymbol{\alpha}_{\mathbf{1}}$ \\
\hline 22400 & 1260 & 0.0371 \\
22401 & 1180 & 0.0371 \\
22402 & 2530 & 0.0370 \\
22403 & 2790 & 0.0370 \\
22404 & 2585 & 0.0370 \\
22405 & 2585 & 0.0370 \\
\hline
\end{tabular}

The area ratio of horizontal fissures has nothing to do with the length of the working face. According to the drilling data, the statistics of the stratification of rock layers under different water levels are shown in Table 4.

Table 4. Stratification number of the strata below different water levels

\begin{tabular}{cccccccccc}
\hline Borehole & $\mathbf{J 7 3}$ & $\mathbf{J 6 4}$ & $\mathbf{J 1 5 0}$ & $\mathbf{J 7 4}$ & $\mathbf{D 1 1}$ & $\mathbf{D 1 2}$ & $\mathbf{5 9}$ & $\mathbf{6 6}$ & Average \\
\hline $\begin{array}{c}5 \mathrm{~m} \\
\text { stratification } \\
\text { number } \\
\quad 10 \mathrm{~m}\end{array}$ & 2 & 2 & 2 & 6 & 3 & 5 & 3 & 2 & 3.13 \\
$\begin{array}{c}\text { stratification } \\
\text { number } \\
\quad 15 m \text { m }\end{array}$ & 2 & 2 & 4 & 9 & 4 & 7 & 5 & 3 & 4.5 \\
$\begin{array}{c}\text { stratification } \\
\text { number }\end{array}$ & 4 & 3 & 8 & 12 & 5 & 8 & 8 & 4 & 6.5 \\
\hline
\end{tabular}

Therefore, when the water level was $\mathrm{Hw}=5,10,15 \mathrm{~m}$, the stratification number of the strata below different water levels was 3,5,7, respectively.

Table 5. Horizontal fracture area ratio

\section{Reservoir number}

coal mine No. 1 underground reservoir

\begin{tabular}{ccc}
\multicolumn{3}{c}{ Horizontal fracture area ratio $\boldsymbol{\alpha}_{2}$} \\
\hline $\mathrm{Hw}=5 \mathrm{~m}$ & $\mathrm{Hw}=10 \mathrm{~m}$ & $\mathrm{Hw}=15 \mathrm{~m}$ \\
0.0714 & 0.0595 & 0.0555
\end{tabular}

The caving angle was $\theta=60^{\circ}$, the working face width was $b=200 \mathrm{~m}$. According to the Formula (8), the calculation results of the reservoir volume are shown in Table 6. 
Table 6. Reservoir volume

\begin{tabular}{cccc}
\hline Working face number & \multicolumn{2}{c}{ Reservoir volume F $(\mathbf{1 0 , 0 0 0}$ cubic metres $)$} \\
\cline { 2 - 4 } 22400 & Hw=5 m & Hw=10 m & Hw=15 m \\
22401 & 125.71 & 250.85 & 375.40 \\
22402 & 117.71 & 234.85 & 351.40 \\
22403 & 252.71 & 504.85 & 756.40 \\
22404 & 278.71 & 556.85 & 834.40 \\
22405 & 258.21 & 515.85 & 772.90 \\
Total & 258.21 & 515.85 & 772.90 \\
\hline
\end{tabular}

According to the Formula (1) and the above calculation results, the reservoir capacity of 2-2 coal mine No. 1 underground reservoir was:

When the water level was $5 \mathrm{~m}$, the reservoir capacity was $139.98 \times 10^{4} \mathrm{~m}^{3}$;

When the water level was $10 \mathrm{~m}$, the reservoir capacity was $248.91 \times 10^{4} \mathrm{~m}^{3}$;

When the water level was $15 \mathrm{~m}$, the reservoir capacity was $357.54 \times 10^{4} \mathrm{~m}^{3}$.

According to the theoretical model, the calculated water storage capacity and actual storage capacity of the No. 1 underground reservoir of No. 2 coal No. 1 in Daliuta coal mine are compared. Table 3 shows the length, width and elevation of the three working faces and the water level. According to the theoretical calculation, the water storage capacity is $44.7648 \times 10^{4} \mathrm{~m}^{3}$. The measured groundwater storage capacity of the three working surfaces is $47 \times 10^{4} \mathrm{~m}^{3}$, and the difference between the theoretical calculation and the actual storage volume value is $4.8 \%$.

Table 7. Comparative table of the theoretical water storage capacity and the actual water storage capacity

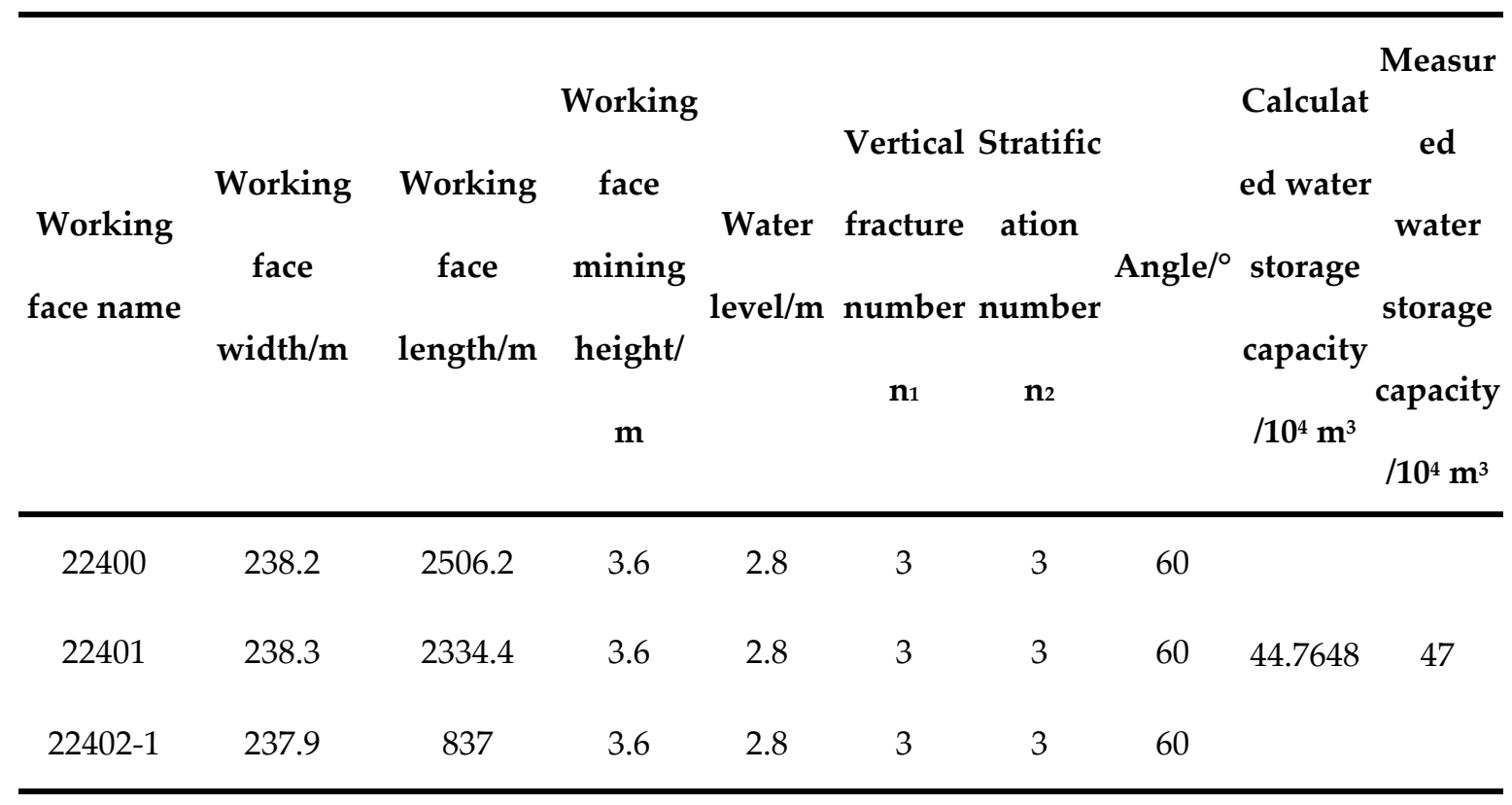




\section{Conclusion}

Coal mine underground water storage plays an important role in the protection and utilization of groundwater in coalmine area, which makes the underground water in the mining area to get recycled, especially in areas that are rich in coal and water, it solves the conflict between water resources protection and coal mining. The water storage coefficient derived from the theoretical model is more based and advanced than the traditional empirical value storage coefficient, and is of great significance in predicting the actual storage capacity of the underground reservoir in a coal mine. Through the establishment of mathematical models to obtain the vertical and horizontal fracture area rate values, and then to derive the water storage coefficient, improve the accuracy of the mine underground reservoir storage capacity calculation. The theoretical water storage calculated by engineering practice has a good match with the actual water storage capacity of the reservoir.

Author Contributions: Conceptualization, Jie Fang; Methodology, Jie Fang; Software, Zhenguo Xing; Validation, Shan Chong; Formal Analysis, Feisheng Feng; Resources, Jiu Huang; Data Curation, Jie Fang; Writing-Original Draft Preparation, Dongjing Xu; Writing-Review \& Editing, Zhenguo Xing; Funding Acquisition, Yunlan He.

Funding: The research is supported by the key national R\&D projects: the key technology integration demonstration of ecological restoration in large coal and power base (20116YFC0501109), and the water resources change law and its ecological impact driven by high intensity coal mining (2016YFC0501102). 


\section{References}

1. Cairney, T., Frost, R.C.. A case study of mine water quality deterioration, Mainsforth Colliery, County Durham. Journal of Hydrology, 1975,25, 275-293.

2. Ladwig, K.J., Erickson, P.M., Kleinmann, R.L.P., Posluszny, E.T.. Stratification in water quality in inundated anthracite mines, eastern Pennsylvania. US Bureau of Mines Report of Investigations RI, 19848837. 35 pp.

3. Younger, P.L.. Mine water pollution in Scotland: nature, extent and preventative strategies. Science of the Total Environment, 2001, 265, 309- 326.

4. Charlotte A. Nuttall and Paul L. Younger. Hydrochemical stratification in flooded underground mines: an overlooked pitfall. Journal of Contaminant Hydrology, ,2004,69:101-114.

5. Joohyung Kim, Jinsuk Choi and Kanghee Park. Comparison of nitrogen and carbon dioxide as cushion gas for underground gas storage reservoir. Geosystem Engineering, 2015, 18(3): 163-167.

6. Gumrah, F.. A numerical simulation study on mixing of inert cushion gas with working gas in an underground gas storage reservoir. Energy Sources, 2000, 22, 869-879.

7. Gumrah, F.. Modeling of underground gas storage in a depleted gas field. Energy Sources, 2005, 27, 913920.

8. Virginie Hamm*, Behrooz Bazargan Sabet. Modelling of fluid flow and heat transfer to assess the geothermal potential of a flooded coal mine in Lorraine, France. Geothermics, 2010, 39:177-186.

9. Esmeralda Peralta Ramos, Katrin Breede,Gioia Falcone. Geothermal heat recovery from abandoned mines: a systematic review of projects implemented worldwide and a methodology for screening new projects. Environ Earth Sci, 2015, 73:6783-6795.

10. S. M. A. Najafi and M. Yaghoubi. Numerical and Experimental Study of an Under-Ground Water Reservoir, Cistern. Water Resour Manage, 2017, 31:1881-1897.

11. GR Watzlaf and TE Ackman. Underground Mine Water for Heating and Cooling using Geothermal Heat Pump Systems. Mine Water \& the Environment, 2006, 25 (1) :1-14.

12. T.Cairney. Utilisation of disused coal mines as water storage reservoirs. Journal of Hydrology, 1973, 19(3):251-258.

13. MP Henton. The Problem of Water Table Rebound After Mining Activity and its Effect on Ground and Surface Water Quality. Studies in Environmental Science, 1981, 17 :111-116.

14. CJ Gandy and PL Younger. Predicting Groundwater Rebound in the South Yorkshire Coalfield, UK. Mine Water \& the Environment,, 2007, 26 (2) :70-78.

15. GU Dazhao. Water resource protection and utilization engineering technology of coal mining in "Energy Golden Triangle" regioon. Coal Engineering, 2014,46(10):34-37.

16. Cao Zhiguo, Li Quansheng, Dong Binqi. Water resource protection and utilization technology and application of caol mining in Shendong mining area. Coal Engineering, 2014,46(10):162-164.

17. GU Dazhao. Theory framework and technological system of coal mine underground reservoir, Journal of China Coal Society, 2015,40(2):239-246.

18. Ramos Ep and Falcone G. Recovery of the geothermal energy stored in abandoned mines. In: Hou MZ, Xie $\mathrm{H}$, Were $\mathrm{P}$ (eds) Clean energy systems in the subsurface: production. Storage and Conversion. Springer, Berlin, 2013, 143-155.

19. C. Andre's, A. Ordo'nez, R. A'lvarez. Hydraulic and Thermal Modelling of an Underground Mining Reservoir, Mine Water Environ, 2017, 36:24-33.

20. Clara Andrés Arias, Almudena Ordóñez Alonso, Rodrigo Álvarez García. Hydrogeological and Thermal Modelling of an Underground Mining Reservoir. Mathematics of Planet Earth, 2014, 419-423. 